\title{
Cost Modeling of Inspection Strategies in Automotive Quality Control
}

\author{
Valtteri Tuominen ${ }^{1}$ \\ ${ }^{1}$ Aalto University, Espoo, Finland \\ Correspondence: Valtteri Tuominen, Oy Mapvision Ltd, Jaakonkatu 2, FI-01620 Vantaa, Finland. Tel: \\ 358-50-346-0790. E-mail: valtteri.tuominen@gmail.com
}

Received: May 7, 2012 Accepted: June 26, 2012 Online Published: July 11, 2012

doi:10.5539/emr.v1n2p33 URL: http://dx.doi.org/10.5539/emr.v1n2p33

\begin{abstract}
Investments and decisions in automotive quality control are often based mostly on qualitative arguments. For being able to justify the need for better quality control, quality needs to be given quantifiable monetary value. In this article a cost model is introduced for comparing different inspection strategies and for creating an understanding of the structure of the costs of bad quality in automotive manufacturing. This model is explained and tested using a case example. Information of the costs of quality used in this case example is gathered from four German automotive companies manufacturing welded assemblies. The same case example is used to compare two different inspection strategies: sampling inspection using a coordinate measuring machine (CMM) and $100 \%$ an in-line inspection using a modern optical measuring system, the Mapvision Quality Gate. The selection of the inspection strategy has a significant effect on the cost of bad quality. The model points out that choosing a correct inspection strategy for quality control will lead to a significant increase in the profit margin of the business.
\end{abstract}

Keywords: cost modeling, quality control, sampling inspection, $100 \%$ inspection, automotive industry

\section{Introducation}

In the field of industrial quality control there is a considerable demand for accurate and flexible real-time optical 3D measuring systems. This demand is derived by the paradigm change in manufacturing systems. The market and products are changing constantly. This and the increasing globalization are shifting the need from dedicated manufacturing lines (DML) towards more flexible reconfigurable manufacturing lines (RMS). To be more productive and responsive, a RMS needs a reconfigurable inspection system (RIM). (Koren \& Shpitalni, 2010) Especially in automotive industry this means that all modern flexible welding and manufacturing systems need to be accompanied with a measuring system reaching the requirements.

Even though this technology would exist, the decision to invest in such a technology must be justified with economic benefits. The calculation of the payback period or return on investment has been a traditional way to prove that an investment is cost-effective. Soukka (2007) presented a new way of applying life cycle analysis (LCA) for understanding profit-making capabilities in process modelling.

Yet, these methods focus on volume, not quality. Traditionally quality is seen as a qualitative feature rather than quantitative feature. Since the monetary value for improving manufacturing process quality is difficult to specify, calculating the return on investment for quality control systems is difficult.

\subsection{Improving Manufacturing Processes}

Improving manufacturing processes has been a focus for a while, in the literature as well as in the practise. The literature presents methods for methods for modelling tolerance design and allocation (Chase, Greenwood, Loosli, \& Hauglund, 1990) using different approaches including non-linear (Ding, Jin, Ceglarek, \& Shi, 2005), neural network (Kopardkar \& Anand, 1995) as well as game theory approaches (Sun Jin, Cheng Zheng, Kuigang $\mathrm{Yu}, \&$ Xinmin Lai, 2010). Tolerance and quality costs have been discussed (Chou \& Chang, 2001) as well as how to optimize costs by distributing components in a multi-plant environment (Tseng \& Huang, 2006).

The literature on quality and process improvement emphasises the importance of designing, planning and controlling the variation and shifting of the manufacturing process (Jeang, 2009). It's also known and shown that low quality losses (good quality) and high manufacturing costs go hand in hand (Jeang, 1994) (Chase, Greenwood, Loosli, \& Haugland, 1990). Yet, the literature knows very little, if any, discussion how to control 
on-line that the planned quality in the manufacturing process is eventually achieved. Surely there is more than plenty of academic discussion of statistical process control (SPC) and six sigma philosophies, but practical studies on on-line control seems to be missing.

\subsection{Cost vs. Quality}

Controlling that the actual manufacturing process meets the requirements set by the design can be understood also as controlling the quality. Controlling the quality has costs. Cost-quality trade-off can be understood as finding the optimum between costs to make good quality and costs which are caused by bad quality. Even though many companies promote quality as the critical success factor, there is no general agreement on the definition what and how to calculate the cost of quality (CoQ). (Schiffauerova \& Thomson, 2006)

Different part manufacturers have different production quality strategies which are commonly based on the requirements of the parts they produce. Requirements can vary based on the functional characteristics of the part, general quality standards set by the industry as well as the specific quality level set by the end customer. Even though a company should adjust its quality strategy based on these requirements, the companies rarely understand how much profit they are losing because of bad quality (Schiffauerova \& Thomson, 2006). This profit loss is caused by needed re-work, disturbances in the process, scrapped products and re-calls and reclaims of delivered products.

\subsection{This Article}

The CoQ -studies found in the literature concentrate on reducing total quality costs by pointing out the areas in operations which cause costs. This article introduces the concept of using a CoQ calculation method as a tool for decision making. Instead of trying to find out the areas of improvement by calculating the $\mathrm{CoQ}$, we try to point out which option is more profitable. The chosen CoQ calculation method is based on the same basic idea as the Crosby model, which calculates the conformance costs and non-conformance costs. (Crosby, 1979) In other words: costs to make good parts and costs of making bad parts.

Controlling the quality can be done in different ways. These different inspection strategies have different effects on the cost of (bad) quality. The model presented in this article focuses on comparing the total cost of quality between different inspection strategies and pointing out the most effective one.

In the last part of this article the created model will be used in an automotive case example to show the dramatic difference in profit making capability between two widely used but opposite inspection strategies. The sensitivity of the model to input estimate accuracy is also evaluated.

\section{Quality Control in Automotive Industry}

Different fields of industries have different kinds of production processes. These different process characteristics lay different requirements and tools for quality control.

Automotive industry, just like all other fields of industries, has its own special characteristics. Welding process, which is the most common process, is fairly complex. Projects are moderately long lasting and expensive. Also different operations are interrelated and dependent on each other. In addition to these challenges, the production volumes are high and all the costs are pushed to the absolute minimum or below. Still, the cost of a defect parts is usually extremely high.

These characteristics result in multiple challenges in the automotive quality control. Since the birth of automotive industry, from the times of Henry Ford, there has been no optimal de facto solution for quality control.

\subsection{Sampling \& SPC}

Sampling inspection means that a small portion of the production is measured, for example every thousandth part or one part a day. From these samples the behavior of the process is estimated using statistics. This approach is called the statistical rocess control (SCP) and has been common in automotive industry since the 1940's. Nowadays it's common that a coordinate measuring machine (CMM) is used for sampling inspection. Commonly the measurement time of a CMM does not allow more parts to be checked in a day.

SPC relies on the assumption that the statistically controlled process follows a normal distribution. The complex welding processes in automotive industry have random disturbances by nature. These disturbances are not seen by the SPC because it is very unlikely that this one defected part would be the sample inspected part. This way the manufacturer delivers defected parts without knowing it.

SPC as well as other statistical approaches require multiple samples to estimate the process reliably. Since the 
study of William Gosset over a century ago the rule of thumb has been 30 samples (Student, 1908). Victor E. Kane (1986) shows that 30 samples are not generally sufficient when LeRoy A. Franklin (1999) emphasizes the necessity of using sample sizes of the order 50 to 100. The practical guideline of AIAG (Automotive Industry Action Group) for testing measurement system capability gives an absolute minimum sample size of 20 and the recommended minimum amount of samples of 50 (Dietrich et al., 1999) (Measurement System Analysis, 2002). In any case dozens of samples are needed for SPC to estimate the process reliably. The requirement of multiple or even dozens of samples to estimate the process means a reaction time of multiple to dozens of days if one part is measured a day. This causes a significant delay in the response time. It might take days or even weeks to detect a trend in the process.

These two characteristic, assumption of normally distributed process and requirement of dozens of samples, have been causing significant problems in the automotive industry.

\subsection{Non-or-all Inspection}

For over half a century there has been an intense - both pragmatic and academic - discussion about the sampling strategy in controlling the quality with sampling inspection (Vardeman \& Jobe, 1999) (Deming, 1982) (Barnard, 1954) (Mood, 1943). Increasing sampling rate increases inspection costs. Reducing sampling rate reduces the amount of information. Since the 1940's the discussion circled over the essential questions of quality control:

- How disastrous is an undetected defective part?

- How often and how quickly can there come a failure to the process?

- What is the cost for receiving a data sample?

During the decades the attempts to create quantitative guidelines for answering these questions resulted to be unsatisfactory for practical use. The principal problem still stood: if your process is stable, you don't need to inspect it because the output of a stable process is confirming. If your process is unstable or if you don't know how your process is, sampling inspection does not give enough information to correct it or to know the process.

Almost half a century later, in the 1980's this discussion was concluded by Deming (1982 \& 1986) by creating a probability and cost model to optimize the sampling rate. The model stated that all parts should be treated identically, meaning that one should either inspect all parts or no parts. Lorenzen (1985) shows that the probability and cost model determines whether $0 \%$ or $100 \%$ inspection plan is the optimal solution. Vander Wiel and Wardeman (1994) extend the theory to be more practical. This generalized model calculates the average inspection and consequence cost of a part:

$$
\left[k_{I}+(1-p) w_{G} k_{G F}+p\left(1-w_{D}\right) k_{D F}+p w_{D} k_{D P}\right]+(1-\pi) p k_{D U}
$$

, where

$k_{I}=$ Cost to inspect one part

$k_{D U}=$ Cost when a defective (bad) part is sent on without inspection

$k_{G F}=$ Cost when a good part fails inspection

$k_{D F}=$ Cost when a defective (bad) part fails inspection

$k_{D P}=$ Cost when a defective (bad) part passes inspection

$p$ = probability for a nonconforming item (bad part)

$w_{G}=$ probability for a conforming item (good part) to fail inspection

$w_{D}=$ probability for a nonconforming item (bad part) to pass inspection

$\pi=$ probability for part to be inspected (sampling rate)

This cost model does not include the costs of a conforming part. This model is intended for comparing costs of inspection and consequences, which is essential for being able to address the cost of bad quality.

The optimal solution for minimizing this equation, or in other words minimizing the average cost of a part, can be reached by either $\pi=1$ or $\pi=0$. Now it could be mathematically proven that sampling is actually never the optimal solution. One should either inspect all parts or no parts.

\subsection{On-line Systems}

To address the problems with sampling inspection there have been developed systems for $100 \%$ inspection. 
These systems are located directly on the production line and are designed to inspect each produced part.

There are a few different technologies used in these systems. Mechanical gauge is the most traditional technology. Fixed laser camera systems as well as robotized laser sensor systems have been used for couple of decades. Newest technology in the industry is completely optical, photogrammetric machine vision system.

\section{Cost of \%d 4 uality}

\subsection{Lost Production Quantities - Cost of Bad Quality?}

Quality factors are usually included when analysing or modelling the production process, at least in some extent. For example Hagberg \& Henriksson (1996) say that the quantity of production $(Q P)$ can be calculated by multiplying the theoretical maximum production $(T M P)$ by availability $(A)$, performance rate $(P)$ and quality rate $(Q)$ :

$$
Q P=T M P \cdot A \cdot P \cdot Q
$$

The unit of the equation can be, for example, mass in a time unit or number of pieces in a time unit. However, the results can also be expressed in monetary units.

Traditionally the quality rate $(Q)$ in the equation is defined as the percentage of conforming (good) parts of the whole production. This rate has traditionally been estimated by product control, called acceptance sampling. In a nut shell it means that samples are taken out of an entity (of a lot of products or a constant process). One inspects the samples and draws conclusion of the complete entity based on the detected nonconformities (bad parts) from the samples. There are countless methods and algorithms for how to sample, including universally known systems for optimizing the acceptance sampling cost efficiency: Military Standard 105, ANSI/ASQC Z1.4, ISO 2859 and Dodge's CSP-1, just to mention a few. (Vardeman \& Jobe, 1999)

Even though this seems fairly logical, there are few major handicaps, at least when applied into automotive industry. First of all the production processes are fairly complex processes having random disturbances making it difficult or impossible to use simple product control. Difference between product and process is that product control has one characteristic: either the product is good or bad. In process control dozens or hundreds of inspection points are controlled. Defining a simple quality rate out of this complex set of variables is impossible or at least difficult and misleading.

Second of all, one single quality rate does not describe different types of defects. In reality the world of automotive manufacturing is not black or white. Different types of defects cause different consequences. Some defects, even though not fulfilling the original specification, can be overlooked if the consequence is insignificant. In the other hand some defects can cause serious consequences and are therefore critical. In these cases using a single quality rate becomes impossible.

The most important handicap is revealed when a lower quality rate is compensated by increasing the other factors. Increasing any of the factors will lead to producing more defective parts. Each defective part has some kind of a consequence cost, at least the scrapping cost. The more defective parts are produced, the higher the consequence costs rise.

\subsection{Consequence Costs}

The highly automated assembly process in automotive industry, as well as in many other modern industries, is designed to have continuous and undisturbed input and is therefore reliable for conforming components. When a non-conforming component gets into the automated assembly process, this can cause numerous kinds of problems.

A defective component can cause the assembly line to get jammed or it might be left undetected during the complete assembly process. Depending on the defect, the consequences differ from downtime and loss of production caused by manual re-work on the line, up to manual disassembly or scrapping of the near final product. In the worst case the completed and delivered car with a defective component needs to be re-called from the public.

All of these issues cause costs. They can be called the consequence costs of bad quality. Surprisingly often these costs are seen as unfortunate or regrettable, but unavoidable part of the manufacturing business. The relation between better quality and reduced consequence costs is usually vague and undefined.

In the following section the consequence costs are addressed more specifically for being able to see the structure and the causality of them. The vague cloud of "bad quality" will be broken into clear and understandable entities which can be assessed. 


\section{Cost Modelling of Bad Quality}

Practically all cost of quality $(\mathrm{CoQ})$ calculation methods are basically alike, they just use different terminology (Schiffauerova \& Thomson, 2006). Practically one calculates the costs included in making good quality and the costs of the consequences of bad quality, or the cost of conformance and non-conformance as Crosby (1979) would put it. In the framework of automotive quality control these costs can be seen as the inspection costs and the consequence cost of defective parts.

Using a generalized cost model consisting of inspection costs and consequence costs of defective parts, Vander Wiel and Wardeman (1994) prove that sampling inspection is never the most cost effective solution. This calculation is explained earlier in 2.2 Non-or-all inspection. As valid as this expression is, it is still too much of a generalization for quality managers to base their decisions on. The biggest handicap in the model of Vander Wiel and Wardeman (1994) is the classification of a defective part: there is one probability and one cost for it.

In reality there are several different types of defects. These different defects each cause completely different consequence costs. Each of these different defects also occurs with a completely different probability. For being able to create a more realistic model for really assessing the true costs, these different types of defects must be incorporated into the same model.

The model also needs to be suitable for different processes and environments. Some simple processes might have only one main defect type while some other process might have ten typical defect types.

Having these requirements acknowledged the original equation for average inspection and consequence cost is reformed as:

$$
\pi k_{I}+\sum_{i=1}^{n}\left\{\pi\left[\left(1-p_{i}\right) w_{G i} k_{G F i}+p_{i}\left(1-w_{D i}\right) k_{D F i}+p_{i} w_{D i} k_{D P i}\right]+(1-\pi) p_{i} k_{D U}\right\}
$$

, where

$i=$ Type of defect

$k_{I}=$ Cost to inspect one part

$k_{D U} i=$ Cost when a type $\mathrm{i}$ defective part is sent on without inspection

$k_{G F i}=$ Cost when a good part fails inspection with a defect warning of type i.

$k_{D F} i=$ Cost when a type i defective part fails inspection

$k_{D P i}=$ Cost when a type i defective part passes inspection

$w_{G i}=$ probability for a type i conforming item (good part) to fail inspection

$p_{i}=$ probability for a type i nonconforming item (bad part)

$w_{D i}=$ probability for a type i nonconforming item (bad part) to pass inspection

$\pi=$ probability for part to be inspected (sampling rate)

With this structure all the main defect types of defects can be assessed in the process by estimating the cost and probability of each defect type specifically. When the defects are categorized into clear and simple real world cases, the assessment can be done rather easily. The factors of the equation of one defect type ( $\mathrm{i}$ ) are presented in Table 1.

Table 1. Factors of the cost model

\begin{tabular}{lcccc}
\hline & \multicolumn{2}{c}{ Good part } & \multicolumn{2}{c}{ Defective part } \\
& Probability & Cost & Probability & Cost \\
\hline Item uninspected & $1-p_{i}$ & 0 & $p_{i}$ & $k_{D U i}$ \\
& & & & \\
Inspected - OK result & $(1-p)\left(1-w_{G i}\right)$ & $k_{I}+0$ & $p w_{D i}$ & $k_{I}+k_{D P i}$ \\
Inspected - NOK result & $(1-p) w_{G i}$ & $k_{I}+k_{G F} i$ & $p\left(1-w_{D i}\right)$ & $k_{I}+k_{D F}$ \\
\hline
\end{tabular}




\section{Case Example}

When trying to estimate the future we run into the same problem no matter what modeling method we use: information and data is available only from the past, not from the future. Sun Jin et al. state that all cars are made with the same concept and therefore historical data can be applied to future planning (Sun Jin et al., 2010).

The main purpose of this paper is to utilize the presented cost model for analysing effects of different inspection strategies. Especially in this case the results based on historical data can be applied more generally.

The following case example is based on information gathered from four German automotive part manufacturers. One of the companies is a major OEM, three of the companies are Tier-1 suppliers. The companies are serving a highly competitive market and therefore are not willing to publish detailed information. Therefore this paper keeps the company names as well as other detailed information confidential. Information of the on-line inspection system is gathered from company Oy Mapvision Ltd. (www.mapvision.fi)

The companies are producing front subframes (a.k.a engine cradles) or instrument panel supports (a.k.a cross car beams). These products are produced with a welding process, which is fairly unstable by nature. Inspection, either $100 \%$ or sampling, is required in this kind of a process. Both part types are also critical for the assembly process of the complete car. This means that a defect in the delivered part will cause consequences on manufacturing plant or on the assembly line.

The production volumes of the studied production lines were between 150000 and 600000 parts a year, which classifies them between medium and high volume production lines. The selling price for these parts were between 20-30 $€$ per part. The fictitious case example manufacturer will produce Instrument Panel Supports with an annual production volume of 300000 parts and a selling price of $25 €$ per part.

The four companies had slightly different calculation methods for estimating the consequence costs. Some companies included lost production volumes when some companies calculated only direct rework or penalty costs. Nevertheless, after further discussion it was possible to create a unified calculation method for the consequence costs. This method is used in the fictitious case example. The structure of the consequence cost is described below in 5.1 .

\subsection{Defects and Consequence Costs}

The structure of the consequence costs in the case example was created based on the discussions with the four companies. The possible defects in manufacturing of the fictitious IPS were simplified to five main defect types. These five defect types are summarized in Table 2.

Type 1 represents a defect of one installation hole being $3 \mathrm{~mm}$ out of tolerance. This causes a $30 €$ cost when the part is re-worked on the assembly line. There is a $1 \%$ probability for this defect type to occur.

Type 2 represents a defect of one installation hole being $10 \mathrm{~mm}$ out of tolerance. This causes the assembly line to stop for a moment for a larger re-work operation. This has a cost of $200 €$ and occurring probability of $0.1 \%$.

Type 3 represents a defect of a missing sub-component, such as a weld nut. This defect can not be re-worked on the assembly line. Due to a missing component, some parts, such as an airbag, can not be bolted to the car. This type of a defect leads to a disassembly or scrapping of the almost completed car. The occurrence probability is one per ten thousand, which means roughly once in two weeks. The cost is $12000 €$, which is almost the price of the car.

Type 4 represents a defect which is not detected even on the final assembly. This type of defect, such as falsely positioned steering wheel mounting bracket, would be noticed before delivering the cars to the public, by the internal or car dealer test drives. In this case the defect can be limited to a certain production batch, say two weeks and 10000 cars. This kind of a post-inspection campaign could have a cost of $30 €$ per car, resulting in a total cost of $300000 €$. This kind of a defect occurs once in a million cars, or once in three years.

Type 5 represents a defect which is detected by the consumers after delivery, such as an out-of-tolerance bracket causing an electric wire to be cut after a year of driving. Even if the car manufacturer can limit this defect to production of a certain day, these 1000 cars need to be re-called from public. The cost for re-calling a car is 1 $800 €$ and the occurrence probability is 0.3 parts per million, meaning once in ten years.

There can also be a one-in-a-billion chance that a world-wide recall is needed for millions of already delivered cars. Costs from this kind of defect rises to billions. Toyota Motor Corporation has proven this in the end of 2009 and beginning of 2010 with a recall campaign concerning over 9 million vehicles and costs rising over 2 billion 
US dollars (Toyota pressroom online, 2010) (BBC News online, 2010). This case example does not include this kind of a horror pictures due to the difficulty to estimate both probability and cost.

Table 2. Defect types with the related costs and probabilities

\begin{tabular}{|c|c|c|c|c|c|c|c|c|c|c|}
\hline \multirow[t]{2}{*}{$\bar{i}$} & \multirow[t]{2}{*}{$\begin{array}{c}\text { Description of } \\
\text { defect }\end{array}$} & \multirow[t]{2}{*}{ Defect causes } & \multicolumn{2}{|c|}{$\begin{array}{c}\text { Cost of delivered } \\
\text { defective part }\end{array}$} & \multicolumn{2}{|c|}{ Probability of case } & \multicolumn{2}{|c|}{$\begin{array}{l}\text { Cost of found } \\
\text { defective part }\end{array}$} & \multicolumn{2}{|c|}{$\begin{array}{c}\text { Probability of } \\
\text { inspection error }\end{array}$} \\
\hline & & & $k_{D P i}$ & $\boldsymbol{k}_{D U i}$ & $p_{i}$ & Occurs & $\boldsymbol{k}_{G F i}$ & $k_{D F i}$ & $w_{G i}$ & $w_{D i}$ \\
\hline 1 & $\begin{array}{c}\text { Installation hole } \\
3 \text { mm out of } \\
\text { tolerance }\end{array}$ & $\begin{array}{c}\text { Re-work on } \\
\text { assembly line }\end{array}$ & $30 €$ & $30 €$ & $1 \%$ & $\begin{array}{l}10 \text { issues } \\
\text { each day }\end{array}$ & $10 €$ & $10 €$ & $0.5 \%$ & $0.5 \%$ \\
\hline 2 & $\begin{array}{l}\text { Installation hole } \\
10 \mathrm{~mm} \text { out of } \\
\text { tolerance }\end{array}$ & $\begin{array}{c}\text { Re-work, } \\
\text { assembly line } \\
\text { stops shortly }\end{array}$ & $200 €$ & $200 €$ & $0.2 \%$ & $\begin{array}{l}2 \text { issues } \\
\text { each day }\end{array}$ & $10 €$ & $10 €$ & $0.2 \%$ & $0.2 \%$ \\
\hline 3 & $\begin{array}{c}\text { Missing } \\
\text { sub-component }\end{array}$ & $\begin{array}{c}\text { Car is } \\
\text { disassembled } \\
\text { or scrapped }\end{array}$ & $12 \mathrm{k} €$ & $12 \mathrm{k} €$ & $\begin{array}{c}0.003 \\
\%\end{array}$ & $\begin{array}{l}0.8 \text { issues } \\
\text { each } \\
\text { month }\end{array}$ & $10 €$ & $10 €$ & $0.01 \%$ & $0.1 \%$ \\
\hline 4 & $\begin{array}{c}\text { Defected } \\
\text { component } \\
\text { detected after } \\
\text { assembly }\end{array}$ & $\begin{array}{c}\text { Re-work of } \\
\text { limited batch } \\
\text { of completed } \\
\text { cars }\end{array}$ & $300 \mathrm{k} €$ & $300 \mathrm{k} €$ & $1 \mathrm{ppm}$ & $\begin{array}{l}0.3 \text { issues } \\
\text { each year }\end{array}$ & $10 €$ & $10 €$ & $0.005 \%$ & $0.005 \%$ \\
\hline 5 & $\begin{array}{c}\text { Defected } \\
\text { component } \\
\text { detected after } \\
\text { delivery }\end{array}$ & $\begin{array}{l}\text { Re-call of } \\
\text { delivered cars } \\
\text { from public }\end{array}$ & $1.8 \mathrm{M} €$ & $1.8 \mathrm{M} €$ & $\begin{array}{c}0.3 \\
\mathrm{ppm}\end{array}$ & $\begin{array}{c}0.09 \\
\text { issues } \\
\text { each year }\end{array}$ & $10 €$ & $10 €$ & $0.005 \%$ & $0.005 \%$ \\
\hline
\end{tabular}

As explained in the beginning, the inspection strategy affects directly to the realized consequence costs. With sampling inspection there is a possibility that a delivered product is defective, which causes a consequence cost. The denser the sampling rate is, the smaller is the probability for the consequence costs to realize, and vice versa.

The relation of the consequence costs and the sampling rate is linear. This relation is shown in Figure 1 with a logarithmic scale to highlight the area of interest, which is around the sampling rate of $1 \%$. With production volumes like in this case example, sampling rates above this using a CMM become practically impossible due to the cycle times and costs.

As seen from Figure 1 the consequence costs start decreasing significantly only after sampling rate of $25 \%-$ $50 \%$. In the other hand with sampling rates less than $5 \%$ the consequence costs stay more or less on the same level.

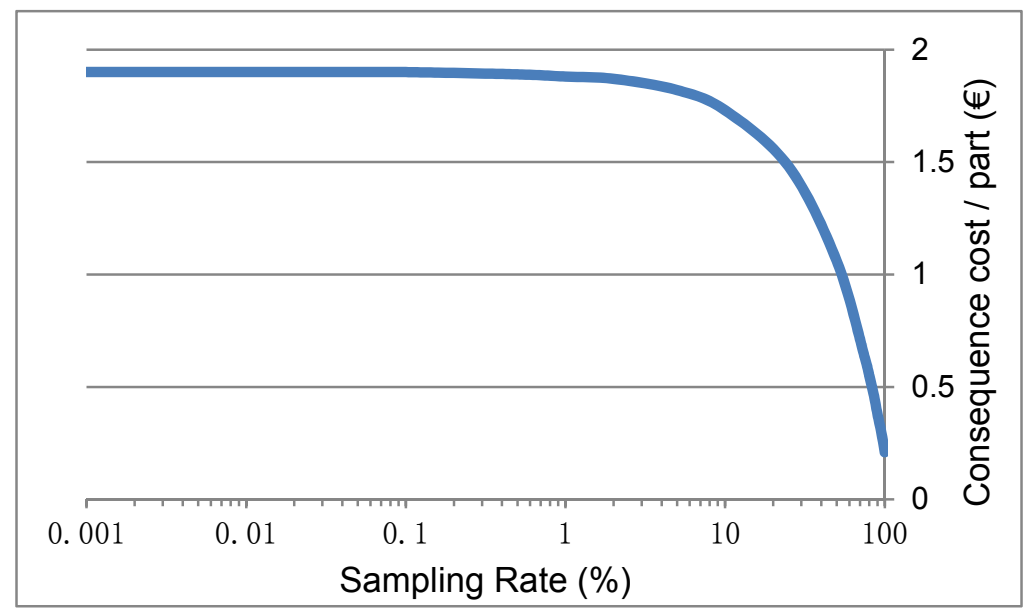

Figure 1. Consequence costs in relation to sampling rate

\subsection{Inspection Costs with $100 \%$ Inspection}

Cost to inspect a part using an on-line system and $100 \%$ inspection is calculated based on same production amounts as above (300 000 parts a year). The investment cost of an on-line measuring system is $250000 €$ and annual operating costs $20000 €$. The production line as well as the on-line system is run for 7 years. This leads to an average inspection cost per part of $0.19 €$, assuming that the system is used to inspect $100 \%$ of the production volume. This is used as the cost of inspection with $100 \%$ inspection. 


\subsection{Inspection Costs with Sampling Inspection}

Sampling inspection is done with a CMM whose cost per hour is $80 €$. The measurement time of a part is 45 minutes. CMM is usually used a pooled resource between numerous projects. Therefore the cost cannot be calculated directly in the same way as the on-line system which is usually dedicated to one only project. The CMM cost information is gathered from the studied companies. This leads to inspection cost of $60 €$ per part. The average inspection cost per produced part with a sampling rate of $1 \%$ would be $60 € * 1 \%=0.60 €$.

The inspection cost is increased in linear relation to sampling rate. This relation is shown in Figure 2 with a logarithmic scale to highlight the area of interest, which is below the sampling rate of $10 \%$. This area covers the practical sampling rates used in automotive industry.

The shown inspection cost does not include the major cost elements of manufacturing the part. As a rule of thumb the material costs are roughly $50 \%$ of the part value. Rest of the $50 \%$ can be roughly seen as the operating costs, scrap costs and profit margin. The selling price of the manufacture part, $25 €$, as well as the material costs, $12.5 €$ are also shown on Figure 2.

As seen from Figure 2 the inspection cost becomes a major portion of the part value when the sampling rate is increased over roughly $1 \%$. On the other hand the inspection cost does not decrease significantly below the sampling rate of $1 \%$.

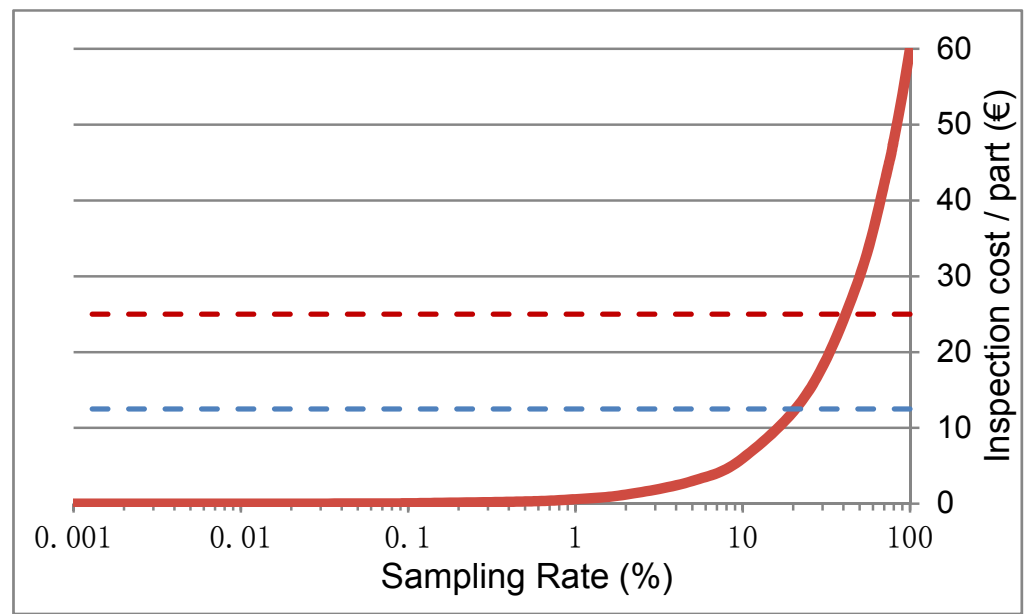

Figure 2. Inspection costs in relation to sampling rate using a CMM. Selling price of the part as upper and material costs as lower dashed lines

\subsection{Optimizing Sampling Rate}

When optimizing the cost efficiency using a sampling inspection strategy we need to include the consequence costs as well as the inspection cost into the calculation. Mathematically the optimal solution would be to have no inspection, sampling rate of $0 \%$. Due to the human nature and the characteristics of automotive industry this is not a real life option. This is why a third element needs to be added to the calculation: the need of process information. This leads to the art of balancing between inspection cost, consequence costs and the unquantifiable need of having some information of the process.

The total average cost of the part as well as the relation between consequence and inspection costs are seen in Figure 3. As seen from the graph, the reasonable sampling rate in terms of cost efficiency would be between $0.1 \%$ $-1 \%$. This means that one part is inspected from once a day to every second hour. These kinds of sampling rates are used quite commonly by automotive part manufacturers. 


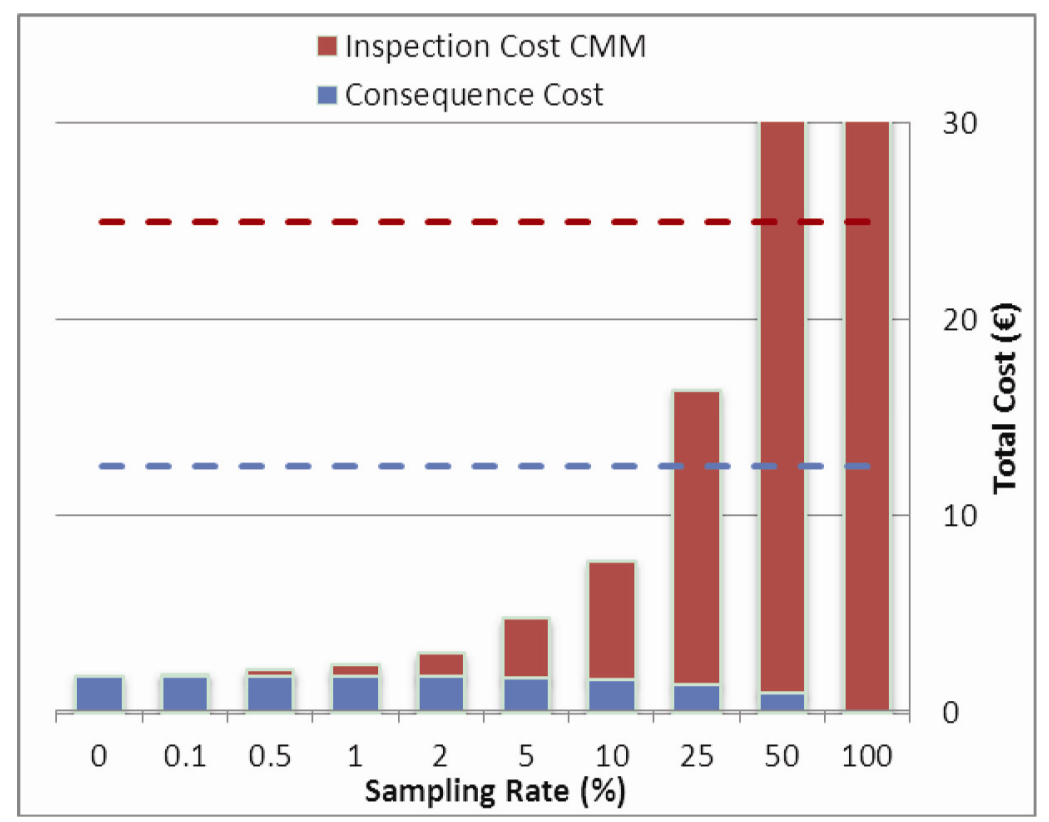

Figure 3. Structure of consequence and inspection costs in relation to sampling rate with CMM. Selling price of the part as upper and material costs as lower dashed lines

\subsection{Sampling vs. $100 \%$ Inspection}

The case example above was carried out in the framework of sampling inspection, comparing different sampling rates. The game changes completely when we include another inspection strategy, $100 \%$ inspection, to the equation.

On-line systems are designed for $100 \%$ inspection and to be done directly on the production line. Due to a different technological approach the inspection cost is reasonable with $100 \%$ inspection, meaning that even though every single part is inspected, the cost per part does not increase significantly. In this case example the inspection cost with an on-line system and $100 \%$ inspection is $0.19 €$ per part, which is in the same order of magnitude than the cost of sampling inspection.

The major difference between the two inspection strategies, sampling and $100 \%$ inspection, comes from the possibility to reduce consequence costs, not from minimizing the inspection cost. In this case example the consequence costs are reduced from $1.90 €$ to $0.21 €$.

Note that the inspection is not assumed to be error free. There is a probability given for inspection error, which leads to the minimum consequence cost of $0.21 €$ per part with $100 \%$ inspection, instead of $0.00 €$.

The total consequence and inspection costs per part with both inspection strategies are shown in Figure 4. Cost breakdown of different inspection strategies is presented in Table 3.

Due to the possibility to reduce consequence costs, the most cost effective solution comes using an on-line system and $100 \%$ inspection strategy. In this case example the cost of the on-line system could be increased 8 -fold and it still would be more cost effective inspection strategy than the sampling inspection with CMM, using any sampling rate.

\subsection{Technology vs. Inspection Strategy}

Understanding the difference between inspection strategies is as important as understanding which technologies support which strategy. This paper highlights the difference between inspection strategies with the assumption that suitable inspection technology is used to support the chosen strategy.

The two different technologies, on-line system and CMM have a fundamental technological difference which reflects also to the cost structure: CMM is commonly used as a pooled resource for multiple projects while an on-line system is dedicated for one project.

Using a CMM the inspection cost per part increases when the sampling rate increases, as seen in Figure 2. This makes also the total part cost to increase relatively. For this reason the CMM is clearly the wrong technological 
choice for $100 \%$ inspection.

In the same way on-line system is the wrong technological choice for sampling inspection with very low sampling rates. The inspection cost per part with an on-line system stays the same regardless what sampling rate is used. When calculating the average inspection cost per part the same operating cost applies and this cost is distributed to all produced parts, not all inspected parts.

See Figure 4 for the comparison of the two technologies in relation to sampling rate. From the figure it can be seen that with a sampling rate of $0.1 \%$ it would be more cost effective to use a CMM instead of an on-line system.

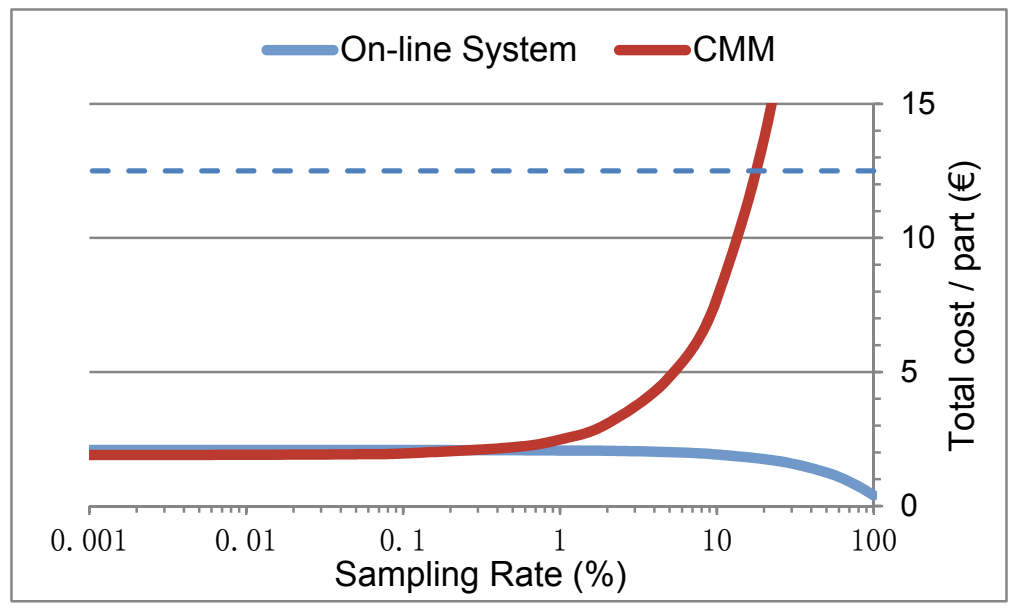

Figure 4. Total costs between CMM and on-line system in relation to sampling rate. Material cost as dashed line

\subsection{Inspection Strategies and Cost of Quality}

This correlates well also with the findings in the literature about cost of quality. Classical and modern views on the cost of quality can be seen in Figure 5. In the classical view (left on Figure 5) it is seen that the total cost of quality will climb dramatically if the quality level is increased to $100 \%$. This is based on the conception that optimum economic quality exists at the level at which the cost of securing higher quality would exceed the benefits of the improved quality (Schiffauerova \& Thomson, 2006).

This classical view is often challenged (Schiffauerova \& Thomson, 2006). The modern view, as seen on right Figure 5, claims that the optimum economic quality level is reached with a $100 \%$ quality level. Associating these two issues, the inspection strategies and cost of quality, it can be said that the different inspection strategies can be seen as technical solutions representing the classical and modern view on cost of quality. Sampling inspection represents the classical approach and $100 \%$ inspection the modern approach. This affinity can be also seen when comparing Figure 4 and Figure 5.
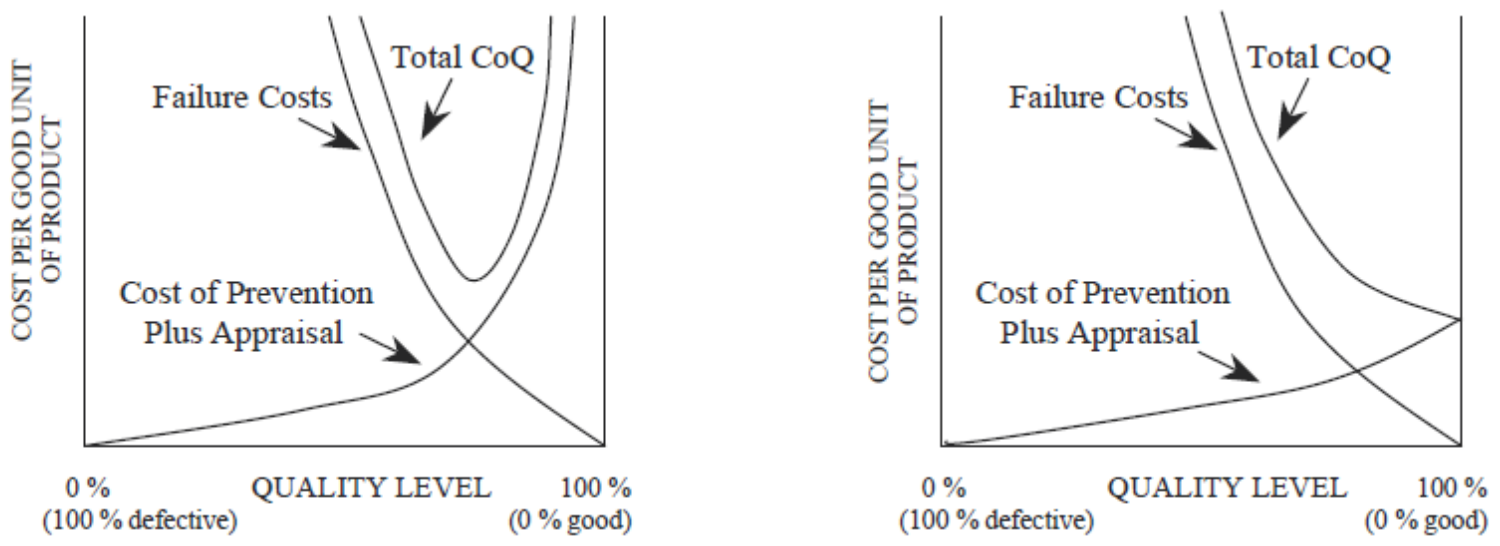

Figure 5. Two views of the structure of the cost of quality (CoQ). Traditional view on the left, modern view on the right (Schiffauerova \& Thomson, 2006) 
Table 3. Cost structure of consequence and inspection costs with different inspection strategies

\begin{tabular}{|c|c|c|c|c|c|c|c|c|c|}
\hline$i$ & Description of defect & Defect causes & $\begin{array}{l}\text { On-line } \\
\text { inspection }\end{array}$ & $\begin{array}{l}\text { Sampling } \\
\text { CMM }\end{array}$ & $\begin{array}{l}\text { Sampling } \\
\text { CMM }\end{array}$ & $\begin{array}{l}\text { Sampling } \\
\text { CMM }\end{array}$ & $\begin{array}{l}\text { Sampling } \\
\text { CMM }\end{array}$ & $\begin{array}{l}\text { Sampling } \\
\text { CMM }\end{array}$ & $\begin{array}{l}\text { Sampling } \\
\text { CMM }\end{array}$ \\
\hline & & & $100 \%$ & $10 \%$ & $5 \%$ & $1 \%$ & $0.5 \%$ & $0.1 \%$ & $0 \%$ \\
\hline 1 & $\begin{array}{l}\text { Installation hole } 3 \\
\text { mm out of tolerance }\end{array}$ & $\begin{array}{l}\text { Re-work on } \\
\text { assembly line }\end{array}$ & $0.15 €$ & $0.29 €$ & $0.29 €$ & $0.30 €$ & $0.30 €$ & $0.30 €$ & $0.30 €$ \\
\hline 2 & $\begin{array}{l}\text { Installation hole } 10 \\
\text { mm out of tolerance }\end{array}$ & $\begin{array}{l}\text { Re-work, } \\
\text { assembly line } \\
\text { stops shortly }\end{array}$ & $0.04 €$ & $0.36 €$ & $0.38 €$ & $0.40 €$ & $0.40 €$ & $0.40 €$ & $0.40 €$ \\
\hline 3 & $\begin{array}{l}\text { Missing } \\
\text { sub-component }\end{array}$ & $\begin{array}{l}\text { Car disassembled } \\
\text { or scrapped }\end{array}$ & $0.01 €$ & $0.33 €$ & $0.34 €$ & $0.36 €$ & $0.36 €$ & $0.36 €$ & $0.36 €$ \\
\hline 4 & $\begin{array}{l}\text { Defected component } \\
\text { detected after } \\
\text { assembly }\end{array}$ & $\begin{array}{l}\text { Re-work on batch } \\
\text { of completed cars }\end{array}$ & $0.01 €$ & $0.27 €$ & $0.29 €$ & $0.30 €$ & $0.30 €$ & $0.30 €$ & $0.30 €$ \\
\hline 5 & $\begin{array}{l}\text { Defected component } \\
\text { detected after } \\
\text { delivery }\end{array}$ & $\begin{array}{l}\text { Re-call of } \\
\text { delivered cars } \\
\text { from public }\end{array}$ & $0.01 €$ & $0.49 €$ & $0.51 €$ & $0.53 €$ & $0.54 €$ & $0.54 €$ & $0.54 €$ \\
\hline \multicolumn{3}{|c|}{ Consequence costs per part } & $0.21 €$ & $1.73 €$ & $1.82 €$ & $1.88 €$ & $1.89 €$ & $1.90 €$ & $1.90 €$ \\
\hline \multicolumn{3}{|c|}{ Inspection cost per part } & $0.19 €$ & $6.00 €$ & $3.00 €$ & $0.60 €$ & $0.30 €$ & $0.06 €$ & $0.00 €$ \\
\hline \multicolumn{3}{|c|}{ Total average cost per part } & $0.40 €$ & $7.74 €$ & $4.82 €$ & $2.48 €$ & $2.19 €$ & $1.96 €$ & $1.90 €$ \\
\hline \multicolumn{3}{|c|}{$\begin{array}{l}\text { Total annual inspection and consequence } \\
\text { costs with } 300 \mathrm{k} \text { production volume }\end{array}$} & $119408 €$ & $\begin{array}{c}2199961 \\
€\end{array}$ & $\begin{array}{c}1325277 \\
€\end{array}$ & $744937 €$ & $657468 €$ & $587494 €$ & $570000 €$ \\
\hline
\end{tabular}

\subsection{Less Cost, More Profit}

The cost savings earned with reducing the costs of bad quality increase the profit margin of the business directly.

In the case example presented above there would be a minimum of $1.50 €$ saving per part between two different inspection strategies, sampling and $100 \%$ inspection. This means an annual saving of $450000 €$. If the sampling rate would have to be higher than $0.1 \%$, for example due to process quality problems, the cost of the sampling inspection strategy increases. This would increase the benefits of $100 \%$ inspection strategy even more.

The annual turnover from a production line is calculated simply by multiplying the selling price of a part with the production volume. In this case example it would be 7.5 million euros. The cost saving of 0.45 million euros would increase the profit margin by 6 percentage points. Based on the information from studied companies usually in automotive industry the target profit margin of a production line is around $5-6 \%$. This means that even if the targeted profit margin would be achieved, the profit could be doubled with reducing the costs of bad quality.

\subsection{Sensitivity of the Estimates}

The outcome of the model is dependent on the quality of the estimates for the probability and consequence costs. To test the sensitivity of the estimates in the model, four different scenarios with different estimation errors were tested.

In the first scenario all the probabilities were given a $500 \%$ error. With this scenario the model shows that using $100 \%$ inspection the annual cost saving is at minimum $42000 €$ compared to $0.1 \%$ sampling inspection. 
Second scenario tested the effect of cost estimation. Similarly, the cost estimates were given a $500 \%$ error. With this scenario using $100 \%$ inspection the annual cost saving is at minimum $13000 €$ compared to $0.1 \%$ sampling inspection.

The third scenario assumed that the non-fatal defect types could be overlooked and therefore they would cause no consequence costs. Defect types 1-3 were removed from the model. With this scenario the model shows that using $100 \%$ inspection the annual cost saving is roughly $133000 €$ compared to $0.1 \%$ sampling inspection.

The fourth scenario assumed that the rare but fatal defect types could not be prevented by inspection. Defect types 4 and 5 were removed from the model. With this scenario the model shows that using $100 \%$ inspection the annual cost saving is roughly $199000 €$ compared to $0.1 \%$ sampling inspection.

\section{Conclusions}

The main purpose of this article was to present an objective tool for managers to assess different choices of inspection strategies. Couple of different methods were briefly overviewed and discussed. Cost modeling approach was taken to estimate the feasibility of these different methods. Defective parts were given a cost and a probability of occurrence. In addition to these consequence costs, the costs of inspection were included in the model. By optimizing these costs of bad quality, the optimal inspection strategy can be selected.

This article addresses the way how the model is created. Having a practical approach using several different types of defects, each having type specific consequences, makes it possible to create an understanding of the true cost structure of bad quality. This practical approach gives the possibility to estimate the costs and probabilities in a more realistic way.

The case example presented a generic manufacturing process of an instrument panel support in automotive industry. The main purpose of the case example was to show in a practical way how the cost model should be used for supporting the decision making of inspection strategies. Input values are based on true manufacturing processes. Using realistic inputs in the model points out also that different inspection strategies have quite a remarkable impact on the business. In the presented case example the profit margin of the production line is doubled in relation to usual automotive target profit margins.

Even though the model is dependent on the estimated costs and estimated probabilities, it shows rigorous analogy on the cost savings. Several scenarios were used for testing estimation errors. Even with a $500 \%$ estimation error either on cost or probability, or even disregarding some major defect types, the cost savings are achieved with the $100 \%$ inspection strategy. This shows that even with inaccurate input data this model can be used to support the decision making process by making the influences of different inspection strategies apparent.

When discussing about the costs of bad quality, this article has addressed the clearly quantifiable costs. The vague costs from reputation and brand image have been neglected due to the difficulties in quantifying them. Also worst case scenarios are not included in the calculations, even though their existence can not be denied.

Due to the complex and hidden nature of the consequence costs, some might deny their existence in the real life. Some might try to address all the consequence costs to the company doing the assembly. Eventually these costs will fall down the food chain in lost business opportunities, lower part prices or otherwise worse contracts.

No matter what you argue, eventually one will face the "cost of bad quality". Investing to better quality control gives the possibility to reduce the costs caused by bad production quality. Different inspection strategies have a direct and even quite significant effect to the business. As the well-known quality control guru William Edwards Deming says: "Improve quality, you automatically improve productivity".

For businessmen this means: "Better quality, more profitable business."

\section{References}

Barnard, G. A. (1954). Sampling Inspection and Statistical Decisions. Journal of the Royal Statistical Society, 16(Ser. B), 151-174.

BBC News online. (2010). Retrieved February 4, 2010, from http://news.bbc.co.uk/1/hi/business/8498036.stm

Chase, K. W., Greenwood, W. H., Loosli, B. G., \& Hauglund, L. F. (1990). Least cost tolerance allocation for mechanical assemblies with automated process selection. Manufacturing Review, ASME, 3(1), 49-59.

Chou, C. Y., \& Chang, C. L. (2001). Minimum-loss assembly tolerance allocation by considering product degradation and time value of money. International Journal of Advanced Manufacturing Technology, 17(2), 139-146. http://dx.doi.org/10.1007/s001700170202

Crosby, P. B. (1979). Quality is Free. New York: McGraw-Hill. 
Deming, W. E. (1982). Quality Productivity and Competitive Position. Cambridge, MA: MIT Center of Advanced Engineering Study.

Deming, W. E. (1986). Out of the Crisis. Cambridge, MA: MIT Center of Advanced Engineering Study.

Dietrich, E. et al. (1999). Measurement System Capability. Reference Manual (Version 2.1 D/E, $22^{\text {nd }}$ ).

Ding, Y., Jin, J., Ceglarek, D., \& Shi, J. (2005).Process-oriented tolerancing for multi-station assembly systems. IIE Trans, 37(6), 493-508. http://dx.doi.org/10.1080/07408170490507774

Franklin, L. A. (1999). Sample size determination for lower confidence limits for estimating process capability $\begin{array}{lllll}\text { indices. Computers \& Industrial } \quad \text { Engineering, } & 36(3),\end{array}$ http://dx.doi.org/10.1016/S0360-8352(99)00154-0

Hagberg, L., \& Henriksson, T. (1996). Profitable maintenance: 8 steps to assured production. Stockholm: Mentor communications.

Jeang, A. (1994). Tolerance design: choosing optimal tolerance specification in the design machined parts. Quality Reliability Engineering International, 10, 2735. http://dx.doi.org/10.1002/qre.4680100107

Jeang, A. (2009). Optimal determination of the process means, process tolerances, and resetting cycle for process planning under process shifting. Journal of Manufacturing Systems, 28(4), 98-106. http://dx.doi.org/10.1016/j.jmsy.2010.04.002

Kane, V. E. (1986). Process Capability Indices. Journal of Quality Technology, 18(1), 41-52.

Kopardkar, P., \& Anand, S. (1995) Tolerance allocation using neural networks. International Journal of Advanced Manufacturing Technology, 10(4), 269-276. http://dx.doi.org/10.1007/BF01186878

Koren, Y., \& Shpitalni, M. (2010). Design of reconfigurable manufacturing systems. Journal of Manufacturing Systems, 29, 130-141. http://dx.doi.org/10.1016/j.jmsy.2011.01.001

Lorenzen, T. J. (1985). Minimum Cost Sampling Plan Using Bayesian Methods. Naval Research Logistics Quarterly, 32, 57-69. http://dx.doi.org/10.1002/nav.3800320111

Mood, A. M. (1943). On the Dependence of Sampling Inspection Plans upon the Population Distributions. The Annals of Mathematical Statistics, 14, 415-425. http://dx.doi.org/10.1214/aoms/1177731361

MSA. (2002). Measurement System Analysis. Reference Manual (3th Edition). Automotive Industry Action Group.

Schiffauerova, A., \& Thomson, V. (2006). A review of research on cost of quality models and best practices. International Journal of Quality and Reliability Management, 23(4), 647-669. http://dx.doi.org/10.1108/02656710610672470

Soukka, R. (2007). Applying the principles of life cycle assessment and costing in process modelling to examine profit-making capability. Acta Universitatis Lappeenrantaesis 275. PhD. diss. Lappeenranta University of Technology.

Student. (1908). Probable error of a correlation coefficient. Biometrika, 6(2-3), 302-310. http://dx.doi.org/10.2307/2331474

Sun, J., Cheng, Z., Kuigang, Y., \& Lai, X. M. (2010). Tolerance design optimization on cost - quality trade-off using the Shapley value method. Journal of Manufacturing Systems, 29, 142-150. http://dx.doi.org/10.1016/j.jmsy.2011.01.003

Toyota pressroom online. (2010). Retrieved October 13, 2010, from http://pressroom.toyota.com

Tseng, Y. J., \& Huang, F. Y. (2006). A multi-plant tolerance allocation model for products manufactured in a multi-plant collaborative manufacturing environment. International Journal of Production Research, 47(3), 733-749. http://dx.doi.org/10.1080/00207540701528792

Vander, W., \& Wardeman. (1994). A Discussion of All-or-None Inspection Policies. Technometrics, 36(1), 102-109. http://dx.doi.org/10.1080/00401706.1994.10485405

Vardeman, S., \& Jobe, J. M. (1999). Statistical Quality Assurance Methods for Engineers. John Wiley \& Sons, Inc., USA. 